\title{
Assessment of genetic diversity in the tropical mulberry Silkworm (Bombyx mori L.) with mtDNA-SSCP and SSR markers
}

\author{
K. Vijayan ${ }^{1,2 *}$, C. V. Nair ${ }^{1}$, S. Raje Urs ${ }^{1}$ \\ ${ }^{1}$ Seri-Biotech Research Laboratory, Central Silk Board, Kodathi, \\ Carmelram Post, Bangalore 560035, Karnataka, India; ${ }^{2}$ Institute of Plant and Microbial \\ Biology, Academia Sinica, Taipei, Taiwan-115, ROC
}

\begin{abstract}
Genetic diversity among 13 tropical nondiapausing silkworm (Bombyx mori L.) genotypes was estimated with simple sequence repeats (SSRs) and mitochondrial DNA (mtDNA)single strand conformation polymorphism (SSCP) markers. Seven SSR primers from silkworm genome and the eight mtDNA primers from the conserved regions of $16 \mathrm{~S}$ and $12 \mathrm{~S}$ ribosomal RNA, cytochrome oxidase I, II and III, and cytochrome B revealed considerable genetic distance among the 13 silkworm genotypes. The heterozygosity generated by the seven pairs of SSR primers varied from 0.098 to 0.396 . The eight pairs of mtDNA primers developed 2 to 10 haplotypes per primer sets. The dendrogram from these markers grouped the silkworm genotypes into different groups, from which potential parents could be selected for developing hybrids for commercial exploitations. Based on cocoon characters and the genetic diversity analysis, Kollegal Jawan was identified as a parent that can be crossed with either BL-23 or Mysore Princess for developing high yielding silkworms to rear commercially during summer and rain seasons.
\end{abstract}

Key words: Bombyx mori, mitochondrial DNA, microsatellites, SSCP, genetic diversity.

\section{التنوع الور اثي في دودة الحرير لنبات التوت الاستو ائي (Bombyx mori L.) بو اسطة mtDNA-SSCP SSR}

\author{
ك. فيجيان، سي. في. ناير، اس. راجي ارس

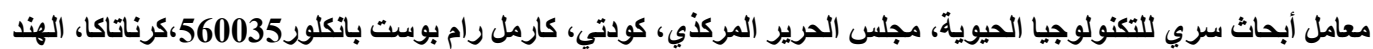

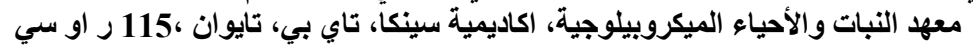

ملغص: التتوع الور اثي بين 13 دودة الحرير nondiapausing الاستو ائية ( بومباي، موري ال).قدرت المورثات لهذه السلالة

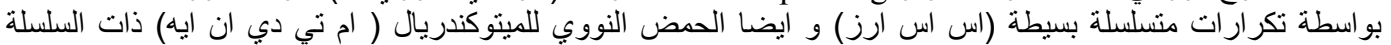

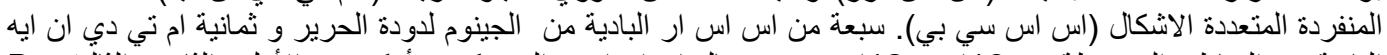

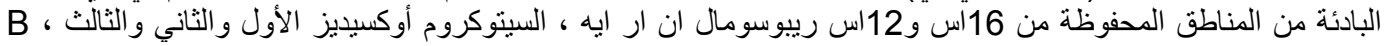

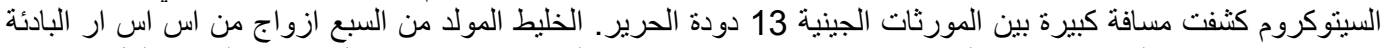

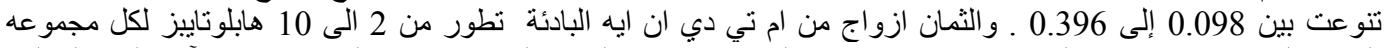

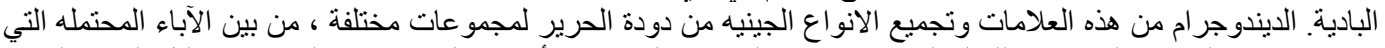

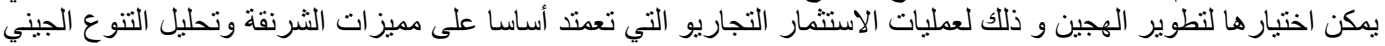

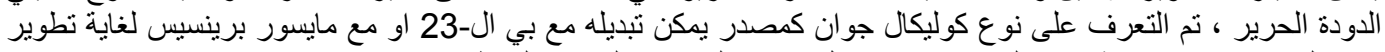

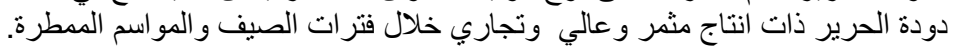

*Corresponding Author, Email: kvijayan01@yahoo.com 


\section{Introduction}

The domesticated silkworm, Bombyx mori, (Bombycidae; Bombycoidea) comprises a large number of traditional genotypes, and modern hybrids and breeding lines developed through systematic breeding. These silkworm genotypes differ much in terms of their geographic origin, morphology, and qualitative and quantitative traits. Silkworms from temperate regions are generally diapausing type (bivoltines) completing two generations per year, whereas those from tropical regions are nondiapausing type (multivoltines) completing five to six generations per year. Nondiapausing silkworms are hardy and can withstand harsh climatic conditions but produce cocoons with less quantity of inferior quality silk, while the bivoltine silkworms are less resistant to adverse climatic conditions but they produce higher quantity of superior quality silk (Datta, 1984). In order to improve the productivity of silk, attempts are being made to improve the nondiapausing silkworms through genetic manipulations and systematic breeding. For any breeding program, it is essential to know the genetic diversity present in the breeding stocks as that will enable the breeder to select appropriate parents depending on the goal of the breeding program.

Simple sequence repeats (SSR), otherwise known, as microsatellites are tandemly repeated DNA sequence motifs present in eukaryotic genomes. SSR markers became very popular because they are highly reproducible, multi-allelic, codominant, following Mendelian inheritance and are amenable to highthroughput automation. Therefore, microsatellites have been used for genetic analysis in both plants and animals (Estoup et al., 1993; Zheng et al., 1996). Microsatellite markers have also been used in silkworms to evaluate the genetic diversity between temperate and tropical silkworm groups (Reddy et al., 1999).
Considering the high resolution and reproducibility, microsatellite markers were selected for the present study to assess the genetic diversity among 13 breeding lines of tropical silkworm genotypes.

Avise (1994) developed another reliable marker systems based on mtDNA variations. Like SSR markers, mtDNA markers are highly variable, can be amplified from a variety of organisms, are haploid and have high evolutionary rate which permits recovery of historical events without the need of sequencing. Further, mtDNA does not undergo recombination, thus, the whole genome is assumed to have the same genealogical history. Thus, mtDNA markers became the marker of choice for population, biogeographic and phylogenetic studies in animals (Hurst and Jiggins, 2005). Since direct detection of single base pair changes in specific sequence via sequencing is cumbersome and expensive, a considerable amount of research is currently directed towards developing indirect methods to achieve this.

The single strand conformation polymorphism (SSCP) technique is one such inexpensive and simple method by which the genomes of many populations have been studied (Black and DuTeau, 1997; Meusnier et al., 2002). In SSCP technique, denatured ds-DNAs are separated on a non-denaturing gel to allow ss-DNA to be separated based on their secondary structure and molecular weight (Matins-Lopes et al., 2001). The SSCP has been used to study the mtDNA variability in many plants and animals (Orita et al., 1989; Sarkar et al., 1992; Sheffield et al., 1993; Marquez and Krafsur, 2003; Natoli et al., 2004).

Damgaard and Sperling (2001) have studied the phylogeny of water spider of genus, Gerris, using mtDNA and nuclear DNA EF-1 $\alpha$. In silkworm also mtDNA variability was used to elucidate its relationship with other silk producing 
insects (Hwang et al., 1999). But, to date mtDNA variability has not been applied to estimate the genetic variability within the species B. mori. The aim of the present study was to assess the genetic diversity among the 13 nondiapausing silkworm genotypes to utilize the information for the development of high yielding hybrids for their rearing during the adverse climatic conditions in summer and rainy seasons.

\section{Materials and Methods}

\section{Silkworm genotypes}

Thirteen nondiapausing (multivoltine) silkworm genotypes, including a pureline developed from a hybrid (Tamilnadu white), collected from tropical sericultural zones in West Bengal (Eastern India), Assam (NorthEastern India), Karnataka (Southern India), Bangladesh and China were used for this study (Table 1). These silkworm genotypes are presently maintained at Central Sericultural Germplasm Resources Centre (CSGRC), Hosur, Tamil Nadu, India, through continuous sib-mating $(>60$ generations).

Table 1. Accession number, name, origin and quantitative traits of 13 silkworm genotypes studied for DNA fingerprinting.

\begin{tabular}{|c|c|c|c|c|c|c|c|c|c|}
\hline $\begin{array}{l}\text { Acc. } \\
\text { no. }\end{array}$ & Name & Origin & $\begin{array}{l}\text { Fecundity } \\
\text { (no) }\end{array}$ & $\begin{array}{l}\text { TLD* } \\
\text { (hrs) }\end{array}$ & $\begin{array}{l}\text { VLD } \\
\text { (hrs) }\end{array}$ & $\begin{array}{l}\text { LWT } \\
(\mathrm{gm})\end{array}$ & $\begin{array}{l}\text { CWT } \\
(\mathrm{gm})\end{array}$ & $\begin{array}{l}\text { SWT } \\
\text { (gm) }\end{array}$ & $\begin{array}{l}\text { SR } \\
(\%)\end{array}$ \\
\hline BMI-0004 & $\begin{array}{l}\text { Tamilnadu } \\
\text { White }\end{array}$ & $\begin{array}{l}\text { India, Tamil } \\
\text { Nadu }\end{array}$ & 448 & 558 & 147 & 24.585 & 1.163 & 0.173 & 14.973 \\
\hline BMI-0007 & $\begin{array}{l}\text { Mysore } \\
\text { princess }\end{array}$ & $\begin{array}{l}\text { India, } \\
\text { Karnataka }\end{array}$ & 488 & 551 & 143 & 27.068 & 1.257 & 0.191 & 15.383 \\
\hline BMI-0019 & Rong Daizo & $\begin{array}{l}\text { China, } \\
\text { tropical }\end{array}$ & 449 & 574 & 169 & 26.294 & 1.368 & 0.191 & 14.104 \\
\hline BME-0012 & BL-23 & India, W.B & 456 & 558 & 147 & 29.182 & 1.322 & 0.219 & 16.671 \\
\hline BMI-0023 & M2 & $\begin{array}{l}\text { India, } \\
\text { Karnataka }\end{array}$ & 418 & 556 & 146 & 23.191 & 1.141 & 0.176 & 14.722 \\
\hline BMI-0009 & $\begin{array}{l}\text { Kollegal } \\
\text { Jawan }\end{array}$ & $\begin{array}{l}\text { India, } \\
\text { Karnataka }\end{array}$ & 511 & 547 & 136 & 28.772 & 1.333 & 0.201 & 15.333 \\
\hline BMI-0001 & Pure Mysore & $\begin{array}{l}\text { India, } \\
\text { Karnataka }\end{array}$ & 453 & 655 & 200 & 19.485 & 1.111 & 0.161 & 14.271 \\
\hline BMI-0018 & Nistari (M) & $\begin{array}{l}\text { India, West } \\
\text { Bengal }\end{array}$ & 425 & 550 & 143 & 21.071 & 1.039 & 0.143 & 13.923 \\
\hline BMI-0019 & Nistari (P) & India, W.B & 419 & 547 & 138 & 23.414 & 1.122 & 0.152 & 13.455 \\
\hline BME-0048 & Nistid (W) & Bangladesh & 400 & 556 & 143 & 21.153 & 1.052 & 0.141 & 13.533 \\
\hline BMI-0002 & Sarupat & India, Assam & 395 & 557 & 146 & 23.652 & 1.143 & 0.171 & 14.935 \\
\hline BMI-0003 & Moria & India, Assam & 424 & 559 & 148 & 24.701 & 1.171 & 0.170 & 14.922 \\
\hline BMI-0017 & Nistari (D) & India, W.B & 405 & 553 & 141 & 23.811 & 1.071 & 0.134 & 13.435 \\
\hline Mean & & & 437 & 563 & 149 & 24.34 & 1.18 & 0.17 & 14.59 \\
\hline $\mathrm{CV}$ & & & 13.29 & 20.61 & 9.15 & 8.69 & 11.17 & 7.10 & 16.29 \\
\hline
\end{tabular}

TLD-Total larval duration, VLD- $\mathrm{V}^{\text {th }}$ instar larval duration, LWT-Weight of 10 numbers of full grown larva, CWT-Weight of single cocoon, SWT-Weight of single shell. SR-Shell ratio expressed as percentage with respect to cocoon weight. WB-West Bengal. The quantitative traits are the mean of 42 generations.

The quantitative characters such as total larval duration, $\mathrm{V}^{\text {th }}$ instar larval duration, weight of full-mature larva, single cocoon weight, single cocoon shell weight, 
shell ratio and fecundity were averages of the values recorded from 40 generations (Table 1). Further information on rearing and reeling characters of these silkworm genotypes are available at http://www. silkgermplasm.com/silkworm-acc.asp.

\section{DNA isolation}

Genomic DNA from each silkworm genotype was isolated following the technique of Nagaraja and Nagaraju (1995). Briefly the moths were frozen in liquid nitrogen and homogenized in pre-chilled mortar and pestle. Five $\mathrm{ml}$ of the extraction buffer $(100 \mathrm{mM}$ Tris-HCl, pH 8.0, $50 \mathrm{mM}$ EDTA and $1 \%$ SDS) and proteinase K (100 $\mu \mathrm{g} / \mathrm{ml}$ ) were added and incubated at $37^{\circ} \mathrm{C}$ for $2 \mathrm{~h}$ with occasional shaking. Saturated phenol ( $\mathrm{pH}$ 8.0) was added, centrifuged and supernatant was taken into a fresh Oakridge tube. The above procedure was repeated with Phenol-chloroform-isoamylalcohol (25:24:1) and chloroform isoamylalcohol (24:1). From the supernatant, DNA was precipitated by adding three volumes of double distilled ethanol. The DNA was hooked out of the solution, dried at room temperature and dissolved in TE buffer $(10 \mathrm{mM}$ Tris-HCl, $1 \mathrm{mM}$ EDTA, $\mathrm{pH}$ 8.0). RNA contamination was removed by incubating the DNA with RNase A $(100 \mu \mathrm{g} / \mathrm{ml})$ at $37^{\circ} \mathrm{C}$ for $1 \mathrm{~h}$. DNA was re-extracted with phenol-chloroform, chloroform and precipitated with ethanol as described earlier.

\section{PCR amplification with SSR primers}

Seven pairs of simple sequences repeat primers designed from silkworm genome (Reddy et al., 1999) were used in this study (Table 2). The PCR cycles and protocols were followed as suggested by Reddy et al. (1999). The PCR products were resolved on denatured $6.0 \%$ polyacrylamide gel containing $8 \mathrm{M}$ Urea in a Pharmacia LKB Macrophor sequencing gel system. The gel was run at a constant voltage of $1000 \mathrm{~V}$ for $6 \mathrm{~h}$. ØX174 DNA digested with Hinf I (MBI Fermentas) was used as size marker. The SSR bands were visualized by staining the gel using a modified protocol of Sanguinetti et al. (1994) as detailed below. The data scoring was as described by Reddy et al. (1999) and Yao et al. (2008).

Table 2. Simple sequence repeat (SSR) primers and the polymorphism generated by them among the 13 silkworm genotypes.

\begin{tabular}{|c|c|c|c|c|c|c|c|}
\hline Primer & 5'-3' Primer sequence & $\begin{array}{l}\text { Target } \\
\text { repeats }\end{array}$ & $\begin{array}{l}\mathrm{T} \\
\left({ }^{\circ} \mathrm{C}\right)\end{array}$ & $\begin{array}{l}\mathbf{M g C l}_{2} \\
(\mathbf{m M})\end{array}$ & $\begin{array}{l}\text { No. of } \\
\text { alleles }\end{array}$ & $\begin{array}{l}\text { Allele } \\
\text { size }\end{array}$ & PIC \\
\hline Sat 211 & $\begin{array}{l}\text { F-GATCGAACTACGCAATTACG } \\
\text { R-CAGCATCCATCCTTATTTAT }\end{array}$ & $(\mathrm{GT})_{10}$ & 49 & 2 & 3 & $280-300$ & 0.396 \\
\hline Sat 951 & $\begin{array}{l}\text { F-ATTGTAACCGATTTGAGAGA } \\
\text { R-ATTCGCACAATAAGTTCACT }\end{array}$ & $(\mathrm{GA})_{23}$ & 48 & 1 & 11 & $110-200$ & 0.232 \\
\hline Sat 892 & $\begin{array}{l}\text { F-CAATAAATGCTTACGAGTTTAA } \\
\text { R-TATCGGTAGTTCCTTGACTT }\end{array}$ & $(\mathrm{GT})_{10}$ & 47 & 3 & 7 & $125-187$ & 0.098 \\
\hline Sat 2550 & $\begin{array}{l}\text { F-GGTCCCTTGAAACTGCGAT } \\
\text { R-CAGAGACCTGCCGGTTGTCGTT }\end{array}$ & $(\mathrm{GA})_{12}$ & 53 & 2 & 6 & $120-160$ & 0.225 \\
\hline Sat 2856 & $\begin{array}{l}\text { F-TTTGGTGTGCAATAAAACAT } \\
\text { R-AGCGACACTTCTGCTATCGT }\end{array}$ & $\begin{array}{l}(\mathrm{CT})_{17} \\
(\mathrm{CT})_{8}\end{array}$ & 49 & 4 & 2 & $146-150$ & 0.192 \\
\hline Sat 2991 & $\begin{array}{l}\text { F-GGTCACGATGCAGTACA } \\
\text { R-GCCTGGAGCCATAACTACTT }\end{array}$ & $\begin{array}{l}(\mathrm{GA})_{6} \\
(\mathrm{GA})_{9}\end{array}$ & 48 & 2 & 11 & $90-249$ & 0.240 \\
\hline Sat 3215 & $\begin{array}{l}\text { F-AGAACCCAGTCCAAGTAATC } \\
\text { R-ACTAATCAACTCGTGACAGT }\end{array}$ & $\begin{array}{l}(\mathrm{GT})_{5} \\
(\mathrm{GT})_{4}\end{array}$ & 46 & 3 & 9 & $70-118$ & 0.396 \\
\hline
\end{tabular}

F-forward; R-reverse 


\section{PCR amplification with mtDNA primers}

Eight mtDNA loci were amplified with degenerate primers designed from conservative regions of $16 \mathrm{~S}$ and $12 \mathrm{~S}$ ribosomal RNA, cytochrome oxidase I, II and III, and cytochrome B (Simon et al., 1994) (Table 3). Amplification was carried out in $25 \mu 1$ reactions consisting of 10X PCR Buffer, 1 unit Taq DNA polymerase (MBI, Fermentas), 2mM
$\mathrm{MgCl}_{2}, \quad 0.4 \mathrm{mM} \quad \mathrm{dNTP}, \quad 0.5 \mu \mathrm{M} \quad$ each primers, $0.2 \mu \mathrm{g} / \mu \mathrm{l}$ bovine serum albumin and 30ng genomic DNA. The thermocycling profile consisted of 30 cycles of $93^{\circ} \mathrm{C} / 35 \mathrm{~s}, 50^{\circ} \mathrm{C} / 18 \mathrm{~s}, 72^{\circ} \mathrm{C} / 18 \mathrm{~s}$ with a final extension of $72^{\circ} \mathrm{C} / 5 \mathrm{~min}$ as suggested by Marquez and Karafsur (2003). PCR amplification products were resolved in $1.5 \%$ agarose gel before being used for polyacrylamide gel electrophoresis.

Table 3. List of mtDNA primers and the diversity estimated among the 13 silkworm genotypes.

\begin{tabular}{|c|c|c|c|c|}
\hline Primer & 5'-3' Primer sequence & $\begin{array}{l}\text { Total } \\
\text { number } \\
\text { of alleles }\end{array}$ & $\begin{array}{l}\text { Allele } \\
\text { size }\end{array}$ & Diversity \\
\hline $16 \mathrm{~S} 1$ & $\begin{array}{l}\text { F-CCGGTCTGAACTCAGATCACGT } \\
\text { R-CGCCTGTTTAACAAAAACAT }\end{array}$ & 4 & $140-400$ & 0.078 \\
\hline $16 \mathrm{~S} 2$ & $\begin{array}{l}\text { F-GGTCCCTTACGAATTTGAATATATCCT } \\
\text { R-ACATGATCTGAGTTCAAACCGG }\end{array}$ & 11 & $70-250$ & 0.149 \\
\hline $12 \mathrm{~S}$ & $\begin{array}{l}\text { F-AAGAGCGACGGGCGATGTGT } \\
\text { R-AAACTAGGATTAGATACCCTATTAT }\end{array}$ & 8 & $120-280$ & 0.135 \\
\hline $\mathrm{CO} 1$ & $\begin{array}{l}\text { F-GGATCACTGATATAGCATTCCC } \\
\text { R-CCCGGTAAAATTAAAATATAAACTTC }\end{array}$ & 7 & $240-400$ & 0.114 \\
\hline $\mathrm{CO} 2$ & $\begin{array}{l}\text { F-GGTCAAACAATTGAGTCTATTTGAAC } \\
\text { R-GGTAAAACTACTCGATTATCAAC }\end{array}$ & 5 & $270-610$ & 0.022 \\
\hline $\mathrm{CO} 3$ & $\begin{array}{l}\text { F-TTATTTATTGCATCAGAAGT } \\
\text { R-TCAACAAAGTGTCAGTATCA }\end{array}$ & 8 & $200-560$ & 0.222 \\
\hline CY-B1 & $\begin{array}{l}\text { F-TATGTACTACCATGAGGACAAATATC } \\
\text { R-ATTACACCTCCTAATTTATTAGGAAT }\end{array}$ & 10 & $120-300$ & 0.071 \\
\hline CO1-TY & $\begin{array}{l}\text { F-TACAATTTATCGCCTAAACTTCAGCC } \\
\text { R-TGTTCCTACTATTCCGGCTCA }\end{array}$ & 7 & $194-600$ & 0.249 \\
\hline
\end{tabular}

F-forward; R-reverse

\section{Single strand conformation polymorphism (SSCP) analysis}

mtDNA variation was evaluated by using single strand conformation polymorphism (SSCP) technique which can detect up to $95 \%$ point mutations in single stranded DNA molecules (Hiss et al., 1994; Marquez and Krafsur, 2003). The PCR products were resolved on native polyacrylamide slab gels $(1.5 \mathrm{~mm} \times$ $200 \mathrm{~mm} \times 200 \mathrm{~mm}$ ) using Bio-Rad Laboratories' PROTEAN $^{\circledR}$ II xi electrophoresis systems, cooled to $3^{\circ} \mathrm{C}$ by circulating refrigerated water. The gel composition was $8.55 \%(\mathrm{w} / \mathrm{v})$ acrylamide, $0.45 \% \quad(\mathrm{w} / \mathrm{v}) \quad \mathrm{N}-\mathrm{N}$-methylene bis acrylamide, $5 \% \quad(\mathrm{v} / \mathrm{v})$ glycerol, $0.15 \%$ TEMED and $0.05 \%(\mathrm{w} / \mathrm{v})$ ammonium 
persulphate in tris-borate-EDTA buffer ( $\mathrm{pH}$ 8.9). From the PCR products, $5 \mu 1$ was mixed with $3 \mu \mathrm{l}$ of SSCP buffer (95\% formamide, $\quad 10 \mathrm{mM} \quad \mathrm{NaOH}, \quad 0.05 \%$ bromophenol blue and $0.05 \%$ Xylene cyanol $\mathrm{FF}$ ), heated to $95^{\circ} \mathrm{C}$ for $5 \mathrm{~min}$ and then cooled on ice. From this mixture $5 \mu 1$ was loaded on to the gel and electrophoresed at a constant voltage of $250 \mathrm{~V}$ for $5 \mathrm{hrs}$.

\section{Silver staining of gels}

The staining of the gel was carried out using a modified protocol of Sanguinetti et al. (1994). After electrophoresis, the gel was fixed in $10 \%$ $(\mathrm{v} / \mathrm{v})$ ethanol along with $0.5 \mathrm{ml} / 100 \mathrm{ml}$ glacial acetic acid for $10 \mathrm{~min}$. and transferred to $0.2 \%(\mathrm{w} / \mathrm{v})$ silver nitrate solution and kept for $10 \mathrm{~min}$. with occasional shaking. The gel was then rinsed in $\mathrm{ddH}_{2} \mathrm{O}$ and transferred to a solution containing $3.0 \%(\mathrm{w} / \mathrm{v})$ sodium hydroxide and $0.5 \%$ formaldehyde. After appropriate development of the bands, the gel was transferred to stop solution containing $1.5 \%(\mathrm{w} / \mathrm{v})$ EDTA. The gel was photographed under white fluorescent light and data were scored directly from the gel on the basis of presence or absence of markers. The PCR amplification with each primer was repeated thrice and those bands appeared consistently across all the three gels in each primer were scored for data analysis following the methods described by Marquez and Karafsur (2003).

\section{Statistical analysis}

For band-sharing analysis, each silkworm genotype was scored for presence (1) or absence (0) of the allelic products to construct a binary matrix as described by Reddy et al. (1999). Each allele was determined on the basis of the size of the band and was treated as independent character. Data were subjected to (i) genetic similarity assessment among the 13 silkworms using Dice's coefficient (D) $=\left(2 \mathrm{~N}_{\mathrm{ab}} /\right.$ $\left.\left(2 \mathrm{~N}_{\mathrm{ab}}+\mathrm{N}_{\mathrm{a}}+\mathrm{N}_{\mathrm{b}}\right)\right)$, where $\mathrm{N}_{\mathrm{ab}}$ is the number of bands that are shared by the genotypes ' $a$ ' and ' $b$ ' and $N_{a}$ is the number of bands present in ' $a$ ' and $\mathrm{N}_{b}$ is the number of bands present in ' $b$ ' (Sneath and Sokal, 1973). A dendrogram was generated from the above matrix using unweighted pair group method with arithmetical averages (UPGMA) (Sneath and Sokal, 1973) on PHYLIP 3.5c software program (Felsenstein, 1993). The congruence between matrices from SSR and mtDNA markers was tested using Mantel's Zstatistics. The significance of the $\mathrm{Z}$-value was determined by comparing the observed value with a critical $\mathrm{Z}$-value obtained from permuted sets of data. This value was derived by calculating $Z$ value for one matrix with a second matrix derived from 1000 permutational data sets. (ii) The mean number of alleles (A) was calculated as $A=\sum_{i=1}^{n} A i / n$, where $A i$ is the number of alleles in the $\mathrm{i}^{\text {th }}$ locus. (iii) The polymorphism information content (PIC) was calculated using the formula PIC $=1-\sum \mathrm{p}^{2} i$, where $\mathrm{P} i$ is the frequency for the $i^{\text {th }}$ microsatellite allele. This value is referred to as heterozygosity and gene diversity (Anderson et al., 1993).

\section{Results}

\section{Phenotypic variability}

The 13 silkworm genotypes showed considerable variability in all the phenotypic traits (Table 1). All the values are averages of data from 40 generations and were obtained from the data bank of CSGRC, Hosur, Tamil Nadu, India (http://www.Silkgermplasm.com/silkwormacc.asp). The total larval duration ranged from $547 \mathrm{hrs}$ in Nistari (P) to $655 \mathrm{hrs}$ in Pure Mysore. The weight of ten fullgrown larvae was in the range of 19.486 gm (Pure Mysore) to 29.182 gm (BL-23). The shell ratio (ratio of shell weight to cocoon weight as percentage) varied from 13.435 in Nistari (D) to 16.675 in BL-23. Among these traits, single shell weigh (SWT) and shell ratio (SR\%) are the 
most important as far as commercial rearing is concerned. Among the 13 genotypes, Mysore princess, BL-23 and Kollegal Jawan have better cocoon characters. Hence, these genotypes have the potentials to be used as parents for commercial silkworm hybrid production, if they are genetically divergent.

\section{Genetic diversity with SSR markers}

The seven sets of microsatellite primers generated a total of 49 alleles among the 13 silk worm genotypes. The number of alleles generated by a single set of primer varied from seven in the locus Sat892 to thirteen in the locus Sat2991. The allele size also varied from $70 \mathrm{bp}$ in the locus Sat3215 to 300bp in the locus Sat211. The heterozygosity estimated for each locus among the 13 silkworm genotypes varied from 0.098 in the locus Sat892 to 0.396 in the loci Sat211 and Sat3215 (Table 2). The pair-wise genetic diversity among the silkworm genotypes ranged from 0.098 between Nistari (P) and Nistari (M) (both genotypes are from West Bengal) to 0.359 between Tamilnadu white (genotype from Tamilnadu) and Sarupat (genotype from Assam). The dendrogram generated by UPGMA grouped 12 silkworms into two major groups leaving a single silkworm as an isolate (Figure 1). The bigger group comprised of nine genotypes, viz., M2, Nistari (M), Nistari(P), Nistid (W), Kollegal Jawan, Pure Mysore, Sarupat, Moria and Nistari (D) while the other one consisted of three genotypes viz, Mysore Princess, Rong Diazo and BL-23. The single isolate was Tamilnadu white. However, the bootstrap values at the nodes indicated that the confidence level is very poor among the different groups.

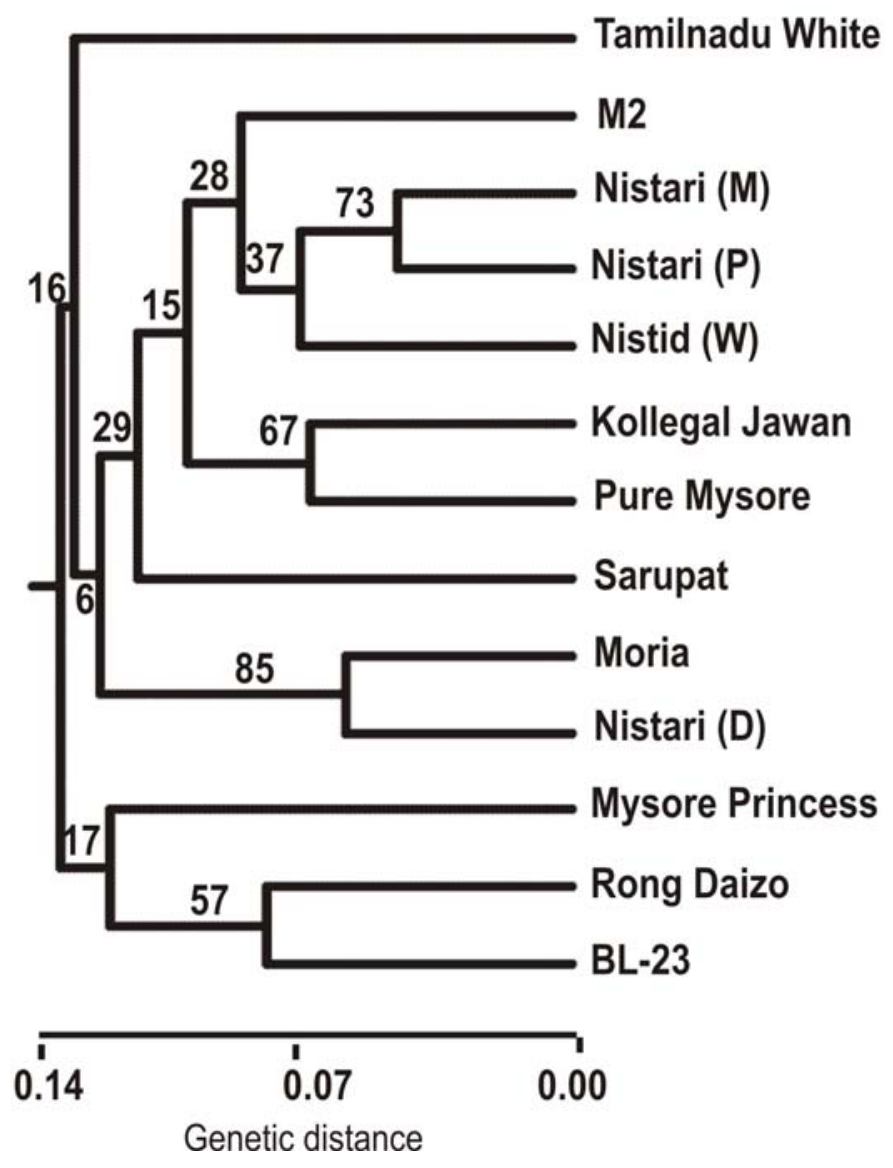

Figure 1. Dendrogram showing genetic relationships among thirteen nondiapausing silkworm genotypes based on microsatellite primers. 


\section{Genetic diversity with mtDNA markers}

The number of haplotypes amplified by each primer set ranged from four at $16 \mathrm{~S} 1$ and CO3 to 11 in 16S2 (Table 3). The band size varied from $70 \mathrm{bp}$ in $16 \mathrm{~S} 2$ to $610 \mathrm{bp}$ in $\mathrm{CO} 2$. The genetic distance among the silkworm genotypes as revealed by each primer set varied from $0.022(\mathrm{CO} 2)$ to $0.249(\mathrm{CO} 1-$ $\mathrm{TY})$. The pair-wise genetic diversity among the silkworm genotypes ranged from 0.016 between Nistari (M) and Moria to 0.302 between Tamilnadu white and Mysore Princess.

The UPGMA analysis arranged the silkworm genotypes into three groups and three isolates on the basis of their relative genetic distance (Figure 2). The first group comprised of four genotypes, Rong Diazo (China), Pure Mysore (Karnataka), Sarupat (Assam), and Nistid (W) (Bangladesh). All these are traditional genotypes originated from geographically different zones. The second group comprised of four silkworm genotypes i.e., Nistari (M) (West Bengal), Moria (Assam), Nistari (D) (West Bengal) and Nistari $(\mathrm{P})$ (West Bengal). In this group, all genotypes are from the eastern and northeastern part of India. The three isolates are Tamilnadu white (Tamil Nadu, the southernmost state of India), Mysore princess (Karnataka) and BL-23 (Karnataka). Among these isolates, Tamilnadu white is having the highest genetic distance from all others. The bootstrap values observed at the nodes of the dendrogram varied from 20 to 99. These significantly higher bootstrap values obtained in all stages of the clustering indicated greater reliability of mtDNA variability.

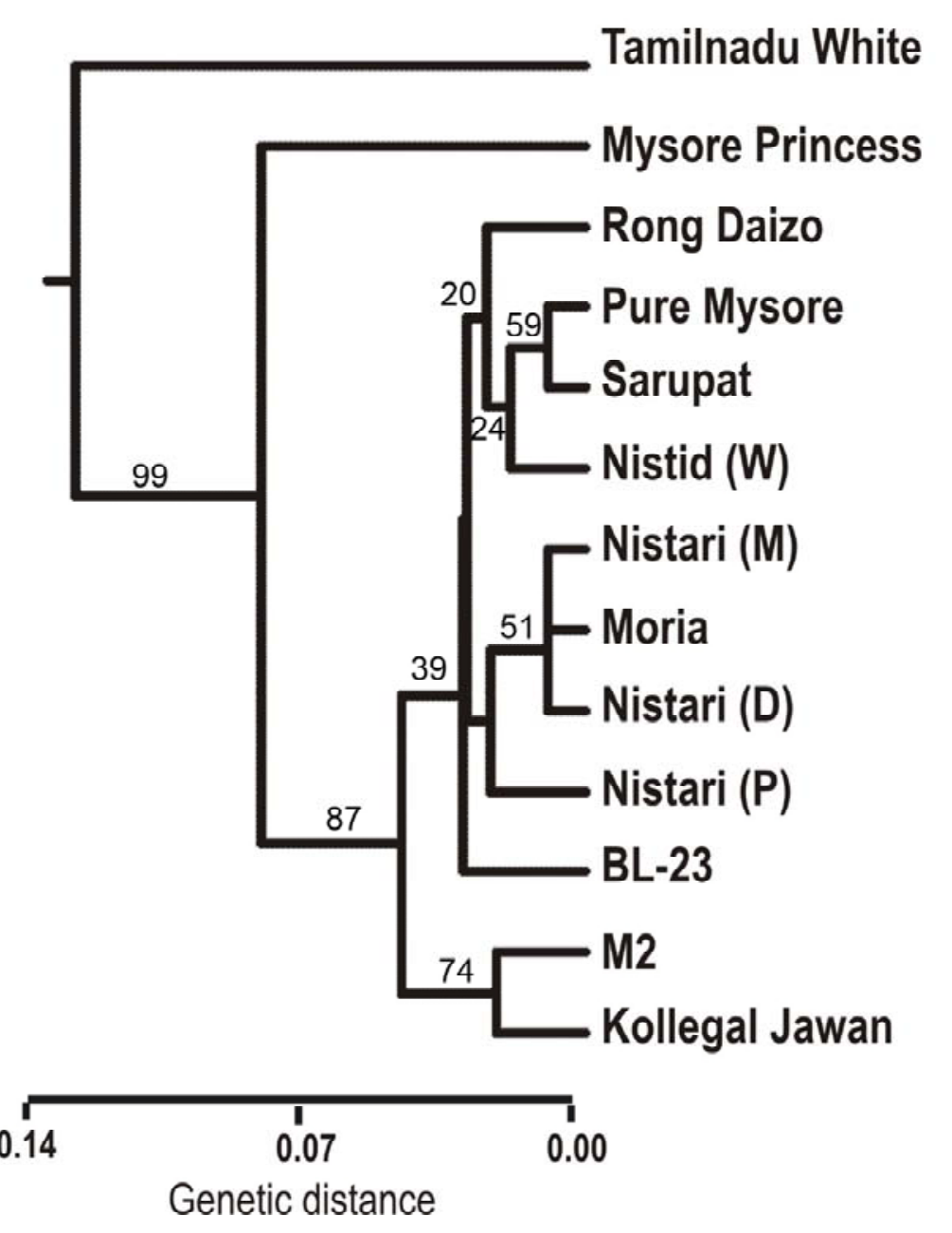

Figure 2. Dendrogram showing genetic relationship among 13 nondiapausing silkworm genotypes based on mtDNA based primers. 
The results of the Mantel's Z-statistics showed a highly significant $(r=0.9003$; $\mathrm{p}<0.001)$ correlation between the genetic distance matrices, derived from mtDNA and SSR markers, which clearly indicates that the results obtained from both marker systems are congruent to each other, though in the dendrograms some silkworm genotypes showed changes in their association.

\section{Discussion}

The present study, with SSR and mtDNA markers, revealed considerable genetic diversity among the 13 non diapausing silkworm genotypes that were developed in India, China and Bangladesh. In an earlier attempt, Reddy et al. (1999) assessed the genetic diversity between diapusing (bivoltine) and nondiapausing (multivoltine) silkworms and found significant genetic differences between these two groups. However, present study deals only with the genetic diversity among 13 breeding lines of nondiapausing silkworms with goal to utilize them for developing hybrids suitable for tropical sericultural zones during summer and rainy seasons. The study revealed presence of considerable genetic diversity among the 13 silkworm genotypes. This information has great impact on silkworm breeding as genetically divergent genotypes with economically important traits such as high cocoon-shell ratio (SR\%), high fecundity, less larval duration are useful for developing hybrids for commercial exploitation. Based on the phenotypic and genetic diversity analyses it was seen that BL2, Kollegal Jawan and Mysore princes have high potential to be used as parents for harnessing the heterosis in commercial hybrids.

Regarding the isolated position of Tamilnadu white in the dendrogram, it is hybrid between a nondiapausing (tropical) and a diapausing (temperate), though it behaves like a nondiapausing genotype
(Thangavelu et al., 1997), the bivoltine genetic back ground of it may have played a role to isolate it from other silkworm genotypes. However, due to continuous inbreeding for many generations this silkworm genotype is now behaving as pure line with nondiapausing characteristics. The grouping of Nistari genotypes as a single group in the dendrograms by both marker systems is another point of interest, as the molecular study suggests that phenotypic variability expressed by these Nistari genotypes is more of environmental than due to genetic reasons. Hence, these Nistari genotypes should be treated as morphotypes rather than different genotypes. The relationship of Nistari with Moria also needs special attention as Moria was collected from Assam, a state adjoining to West Bengal and sericulture commodities moved been between these two states without much hindrance. Thus, it is presumed that Moria may have evolved from Nistari rather recently. Hence, these two silkworm genotypes should not be used for heterosis breeding.

The study also revealed considerable differences in the potentials of the two marker systems used in this study. The number of polymorphic alleles is higher in the nuclear microsatellites as compared to the haplotypes generated by the mtDNA primer sets. This could be due to the variations in the rate of evolution as the microsatellite markers are mostly free from the constraints of selection, hence accumulate more substitutions. It can also undergo recombinations and other changes that are caused by transposons. Burgess et al. (2001) reported that microsatellites evolve and mutate more rapidly than other areas in the nuclear DNA, through a process called slip-strand impairing during the DNA replication. Although mitochondrial DNA (mtDNA) has been used for genetic diversity, phylogenetic and population-genetic studies in insects (Behura, 2006), it has 
certain limitations such as maternal inheritance and absence of recombinations (Kondo et al., 1990; Gyllensten et al., 1991; Skibinski et al., 1994). Additionally, Ballard and Whitlock (2004) reported that mtDNA evolution is nonneutral with sufficient regularity to question its utility as a marker for genomic history. Another problem associated with mtDNA markers is the effective population size, which is only one fourth of the same for nuclear sequences; therefore, mtDNA lineages have a much faster lineage sorting rate and higher allele extinction rate. Consequently, the genetic diversity can be underestimated, the evolutionary relationships could be oversimplified, uncertainty in genealogical analysis may increase due to the increased probability of more missing links in mitochondrial haplotypes, and remote population processes may not be detected correctly with mtDNA markers (Zhang and Hewitt, 2003). Therefore, it is not surprising that a low genetic diversity was observed with mtDNA markers. Earlier, Hwang et al. (1999) used mtDNA sequence variability to assess the genetic relationship between Bombycidae (B. mori and B. mandarina) and Saturniidae (Antheraea yamamai and Antheraea pernyi) and this study revealed a monophyletic relationship for Bombycidae and Saturniidae. Nonetheless, studies with mtDNA variability in other insects like ladybirds (Palenko et al., 2004) showed that CO1 is very useful for assessing intraspecific and interspecific genetic variability.

In most of the earlier reports on mtDNA polymorphism used direct sequencing to detect the nucleotide variability. Since direct detection of single base pair changes in specific DNA fragment via sequencing is cumbersome and expensive, single strand conformation polymorphism (SSCP) technique is increasingly being used for phylogenetic studies (Black and DuTeau, 1997). Nonetheless, it is interesting to note that in the present study, 12S, 16S2, CO3 and CO1-TY loci detected 0.135 to 0.249 heterozygosity among the 13 silkworms. This moderate heterozygosity revealed by the mtDNA among the tropical nondiapausing silkworm breeds indicates that these silkworm genotypes may have evolved from a common ancestor, as reported by Hwang et al. (1999). This finding was further supported by the higher genetic diversity observed with SSR markers. Thus, these land genotypes could be used for breeding purposes to harness heterosis for yield attributing traits. Further, it could also be seen that among the SSR primer pairs used in this study, Sat211, Sat2550, Sat2991, Sat 951 and Sat3215 are more useful for phylogenetic studies in the silkworm $B$. mori as they revealed higher polymorphism. Another point, which needs attention, is the higher PIC value observed by Reddy et al. (1999) for each of these primers. This higher PIC value could be due to the selection of widely varying genotypes from two distinct groups viz., diapausing and nondiapausing silkworms originated from tropical and temperate regions.

Thus, it can be concluded from this study that considerable genetic is diversity present among the 13 silkworm genotypes. Based on cocoon characteristics and genetic diversity three potential parents such as Kollegal Jawan, Mysore Princess and BL-23 were identified. Using these genotypes heterosis breeding is quite possible for exploiting the hybrid vigour. Similarly, all the Nistari genotypes have little genetic differences among themselves. Therefore, these genotypes may be clubbed together under a single genotype.

\section{References}

Anderson, J. A., G. A. Churchill, J. E. Autrique, S. D. Tanksley and M. E. Sorrels. 1993. Optimizing parental 
selection for genetic linkage maps. Genome 36:181-186.

Avise, J. C. 1994. Molecular markers, Natural history and evolution. Chapman and Hall, New York.

Ballard, J. W. O. and M. C. Whitlock, 2004. The incomplete natural history of mitochondria. Mol. Ecol. 13:729744.

Black, W. C. V. and N. C. Duteau. 1997. RAPD-PCR and SSCP analysis for insect population genetic studies. In: J. M. Crampton, C. B. Beard and C. Louis (Eds). pp. 361-383. Molecular Biology of Insect Disease Vectors: A Methods Manual. Chapman and Hall, London.

Behura, S. K. 2006. Molecular marker systems in insects: current trends and future avenues. Mol. Ecol. 15:30873113.

Burgess, T., M. J. Wingfield. and B. W. Winfield. 2001. Simple sequence repeat markers distinguish among morphotypes of Sphaeropsis sapinea. Appl. Environ. Microbiol. 67:354362.

Damgaard, J. and F. A. H. Sperling. 2001. Phylogeny of the spider genus Gerris Fabricius (Heteroptera: Garridae) based on COI mt DNA, EF-1 $\alpha$ nuclear DNA and morphology. System. Entomol. 26:241-254.

Datta, R. K. 1984. Improvement of silkworm races, Bombyx mori L., in India. Sericol. 24:393-415.

Estoup, A., M. Solignac, M. Harry and J. M. Cornuet. 1993. Characterisation of (GT)n and (CT)n microsatellites in two insects species: Apis mellifera and Bombus terrestris. Nucleic Acids Res. 21:1427-1431.

Felsenstein, J. 1993. PHYLIP (Phylogeny inference package) version $3.5 \mathrm{c}$. Department of Genetics, Univ. Washington, Seattle.

Gyllensten, U., D. Wharton, A. Josefsson. and A. C. Wilson. 1991. Paternal inheritance of mitochondrial DNA in mice. Nature 352:255-257.

Hiss, R. H., D. E. Norris, C. H. Dietrich, R. F. Whitcomb, D. F. West, C. F. Bosio, S. Kambhampati, J. Piesman, M. F. Antolin and I. V. W. C. Black. 1994. Molecular taxonomy using single-strand conformation polymorphism (SSCP) analysis of mitochondrial ribosomal DNA genes. Insect Mol. Biol. 3:171-182.

Hurst, G. D. D. and F. M. Jiggins. 2005. Problems with mitochondrial DNA as a marker in population, phylogeographic and phylogenetic studies: the effects of inherited symbionts. Proc. Royal. Soc. London. B. 272:1525-1534.

Hwang, J. S., J. S. Lee, T. W. Goo, E. Y. Yun, H. R. Sohn, H. R. Kim, and O. Y. Kwon. 1999. Molecular genetic relationship between Bombycidae and Saturniidae based on the mitochondrial DNA encoding of large and small rRNA. Gen. Anal. 15:223-228.

Kondo, R., Y. Satta, E. T. Matsuura, H. Ishiwa, N. Takahata and S. I. Chigusa. 1990. Incomplete maternal transmission of mitochondrial-DNA in Drosophila. Genet. 126:657-663.

Marquez, J. G. and E. S. Krafsur. 2003. Mitochondrial diversity evaluated by the single strand conformation 
polymorphism method in African and North American house flies (Musca domestica L.). Insect Mol. Biol. 12:99-106.

Martins-Lopes, P., H. Zhang and R. Koebner. 2001. Detection of single nucleotide mutation in wheat using single strand conformation polymorphism gels. Plant Mol. Biol. Report. 19:159-162.

Meusnier, I., M. Valero, C. Destombe, C. Gode, E. Desmarais, W. Bonhomme, W. T. Stam and J. L. Olsen. 2002. Polymerase chain reaction-single strand conformation polymorphism analyses of nuclear and chloroplast DNA provide evidence for recombination, multiple introductions and nascent speciation in the Caulerpa taxifolia complex. Mol Ecol. 11:2317-2325.

Nagaraja, G. M. and J. Nagaraju. 1995. Genome fingerprinting in silkworm Bombyx mori using random arbitrary primers. Electrophoresis. 16:16331638.

Natoli, A., V. M. Peddemors and A. R. Hoelzel. 2004. Population structure and speciation in the genus Tursiops based on microsatellites and mitochondrial DNA analysis. J. Evol. Biol. 17:363-375.

Orita, M., H. Iwahana, H. Kanazana, K. Hayashi and T. Sekiya. 1989. Detection of polymorphism of human DNA by gel electrophoresis as single-strand conformation polymorphism. Proc. Natl. Acad. Sci. USA 86:2766-2770.

Palenko, M. V., D. V. Mukha and I. A. Zakharov. 2004. Intraspecific and interspecific variation of the mitochondrial gene of cytochrome oxidase I in ladybirds (Coleoptera: Coccinellidae). Russian J. Gen. 40:146-151.

Reddy, K. D., E. G. Abraham and J. Nagaraju. 1999. Microsatellites in the silkworm Bombyx mori: Abundance, polymorphism, and strain characterisation. Genome 42:1057-1065.

Sanguinetti, C. J., E. D. Neto and A. J. G. Simpson. 1994. Rapid silver staining and recovery of PCR products separated on polyacrylamide gels. Biotech. 17:915-919.

Sarkar, G., H. S. Yoonm and S. S. Sommer. 1992. Screening for mutations by RNA single strand conformation (rSSCP): comparison with DNA-SSCP. Nucleic Acids Res. 20:871-878.

Sheffield, V. C., J. S. Beck, A. E. Kwitek, D. W. Sandstrom and E. W. Stone. 1993. The sensitivity of single-strand conformation polymorphism analysis for the detection of single base substitution. Genomics 16:325-332.

Simon, C., F. Frati, A. Beckenbach, B. Crespl, H. Liu and P. Flock. 1994. Evolution, weighting and phylogenetic utility of mitochondrial gene sequence and a compilation of conserved polymerase chain reaction primers. Ann. Entomol. Soc. Am. 87:651- 701.

Skibinski, D. O. F., C. Gallagher and C. M. Beynon. 1994. Mitochondrial DNA inheritance. Nature 368:817818.

Sneath, P. H. and R. R. Sokal. 1973. Numerical taxonomy. W. H. Freeman, San Francisco. 
Thangavelu, K., P. Mukherjee, R. K. Sinha, T. S. Mahadevamurthy, S. Mukherjee, N. K. Sahni, P. Kumaresan, P. A. Rajarajan, B. Mohan, and S. Sekar. 1997. Catalogue on Silkworm (Bombyx mori L.) Germplasm. Vol.I. Silkworm and Mulberry Germplasm Station, Hosur, Tamil Nadu, India. Pp.138.

Yao, Q. L, P. Fang, K. C. Kang and G. T. Pan 2008. Genetic diversity based on SSR markers in maize (Zea mays L) landraces from Wuling mountain region in China. J. Genet. 87:287291.
Zhang, D. X. and G. M. Hewitt. 2003. Nuclear DNA analyses in genetic studies of populations: practice, problems and prospects. Mol. Ecol. 12:563-584.

Zheng, L., M. Q. Benedict, A. J. Cornel, H. F. Collins and F. C. Kafatos. 1996. An integrated genetic map of human malaria as vector mosquito Anopheles gambiae. Genet. 143:941952. 